\begin{tabular}{|c|c|}
\hline $\begin{array}{l}\text { Tradición autobiográfica y autoficción en la literatura hispanoamericana } \\
\text { contemporánea }\end{array}$ & Titulo \\
\hline Negrete Sandoval, Julia Érika - Autor/a; & Autor(es) \\
\hline $\begin{array}{l}\text { De Raíz Diversa. Revista Especializada en Estudios Latinoamericanos (Vol. } 2 \text { no. } 3 \\
\text { ene-jun 2015) }\end{array}$ & En: \\
\hline México D.F. & Lugar \\
\hline $\begin{array}{l}\text { Programa de Posgrado en Estudios Latinoamericanos, Universidad Nacional } \\
\text { Autónoma de México }\end{array}$ & Editorial/Editor \\
\hline \multirow[t]{2}{*}{2015} & Fecha \\
\hline & Colección \\
\hline $\begin{array}{l}\text { Lejeune, Philippe; Doubrovsky, Serge; Autobiografía; Literatura latinoamericana; } \\
\text { América Latina; }\end{array}$ & Temas \\
\hline Artículo & Tipo de documento \\
\hline $\begin{array}{l}\text { "http://biblioteca.clacso.edu.ar/Mexico/ppel-unam/20160621050647/Negrete_Julia_Tradicion_autobiografica_y_autoficcion_en_la_literatur } \\
\text { a_hispanoamericana_contemporanea.pdf" }\end{array}$ & URL \\
\hline $\begin{array}{l}\text { Reconocimiento-No Comercial-Sin Derivadas CC BY-NC-ND } \\
\text { http://creativecommons.org/licenses/by-nc-nd/2.0/deed.es }\end{array}$ & Licencia \\
\hline
\end{tabular}

Segui buscando en la Red de Bibliotecas Virtuales de CLACSO http://biblioteca.clacso.edu.ar

Consejo Latinoamericano de Ciencias Sociales (CLACSO)

Conselho Latino-americano de Ciências Sociais (CLACSO)

Latin American Council of Social Sciences (CLACSO)

www.clacso.edu.ar

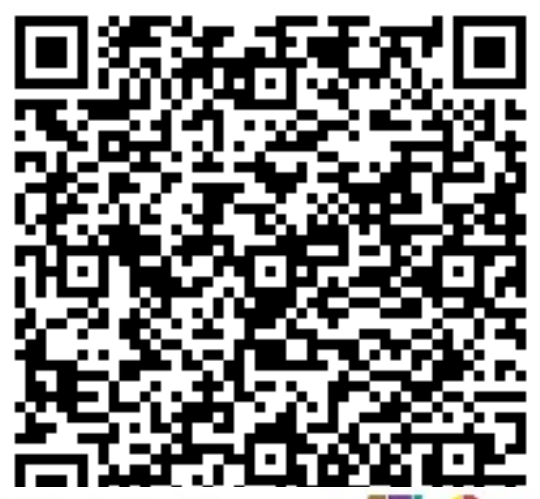

Consejo Latinoamericano de Ciencias Sociales

Conselho Latino-americano de Ciências Sociais 


\title{
Tradición autobiográfica y autoficción en la literatura hispanoamericana contemporánea
}

\author{
Julia Érika Negrete SandovaL*
}

RESUMEN: La autoficción se ha convertido en una tendencia artística y de reflexión teórica desde que, en 1977, Serge Doubrovsky introdujera el término para describir su novela Fils, con la que desafía uno de los principios fundamentales de la autobiografía: la identidad nominal entre autor, narrador y personaje, y con ello el pacto autobiográfico propuesto por Philipe Lejeune en 1975. Si bien su origen se encuentra en la autobiografía y las dificultades teóricas que comenzó a plantear desde la década de 1960, la autoficción ha seguido la senda de la escritura novelística y ha abierto otras brechas al estudio de las consecuencias que acarrea la presencia del autor en el texto. La literatura hispanoamericana, aunque un tanto ajena al debate teórico, incursionó por su cuenta en este campo recién descubierto en Francia. En este ensayo propongo rastrear el desarrollo de una tradición autobiográfica en Hispanoamérica y su relación con el surgimiento de textos que, al apropiarse del yo autobiográfico, adquirieron semejante factura a lo que se conoce como autoficción.

Palabras Clave: Autobiografía, autoficción hispanoamericana, autor.

AbstraCt: Autofiction has become an artistic and theoretical tendency since 1977, when Serge Doubrovsky invented the term to describe his novel Fils, in which he challenged the fundamental principles of autobiography — the identity of name of author, narrator and main character, as well as the autobiographical pact proposed by Philippe Lejeune in 1975. Even though autobiography and its theoretical difficulties (laid out since the 60's) are the origin of autofiction, it has followed the route of fictional writing and has opened other doors to the study of the consequences derived from the presence of the author in the text. Although Spanish American literature was unaware of the theoretical discussion, it explored on its own this field recently discovered in France. In this paper I propose to track the development of an autobiographical tradition in Spanish America and its relation with the origin of texts that, as they usurped the autobiographical self, developed similar characteristics of what we know as autofiction.

KEY WORDs: Autobiography, Spanish American autofiction, author.

Recibido: 09 de noviembre de 2014. ACEPTAdo: 10 de diciembre de 2014 .

\footnotetext{
Posdoctorante del Programa de Posgrado en Estudios Latinoamericanos de la UNAM. $<$ juli7mas@hotmail.com>
} 
La verdad de una novela es siempre la lucha que el escritor entabla consigo mismo; con ese y eso que está creando. La composición es simplemente la confusión de las palabras y los hechos; la confusión de estas cosas en el tiempo y en el espacio; la confusión que es su propia identidad.

Salvador Elizondo, El hipogeo secreto

$\mathrm{E}$

n el siglo xx el género autobiográfico modificó sus estructuras tradicionales para renovarse. La inestabilidad de la concepción del "yo" ha participado en gran medida en la configuración de un extenso espacio autobiográfico compartido por la autobiografía, las memorias, el diario íntimo, la novela autobiográfica y la autoficción; espacio que ha tendido a eliminar las fronteras entre los géneros y que exige, a fuerza de repeticiones, examinar las circunstancias que acercaron la autobiografía al terreno movedizo de la ficción y que indujeron a ésta a apropiarse del "yo", entidad compleja, más rica para sus propósitos creativos que cualquier otra realidad.

En lo que toca a la práctica autobiográfica en Hispanoamérica hay aún mucho que decir, pues las circunstancias sobre las que se funda su desarrollo han seguido caminos distintos de los modelos venidos de Europa, y, por lo mismo, piden una lectura que, sin ignorar esos modelos, construya sus propios parámetros de interpretación. Cuando Jean Jacques Rousseau escribe Las confesiones a finales del siglo XVIII, con plena conciencia de su individualidad, las sociedades hispanoamericanas se debatían en medio de las tensiones por definir su identidad y sobrevivir a la opresión del país conquistador. Los siglos siguientes no fueron más afortunados, ya que continuaron las luchas por consolidar naciones independientes o poner fin a años de dominación bajo regímenes políticos dictatoriales. Sin embargo, una vez superados esos obstáculos, aun cuando los problemas actuales no son menores, los países de Hispanoamérica han asimilado con rapidez los cambios que, sobre todo a partir de la segunda mitad del siglo $\mathrm{xx}$, han homogeneizado la cultura occidental.

Aunque mi objetivo aquí no es el estudio de la autobiografía propiamente dicha, sí me propongo sopesar su estado tanto en la producción literaria hispanoamericana de las décadas de 1960 y 1970, como en el marco de las teorías que se gestaron por los mismos años y que propiciaron la creación de la autoficción, modalidad genérica que marcó el impase en los estudios autobiográficos actuales. De este modo, aspiro a entrever los modos de representación del yo o, para usar el término de Sylvia Molloy, "las figuraciones del yo", que animan una escritura tendiente a apropiarse de lo que otrora fuera privilegio de la autobiografía: el autor. 


\section{EL GÉNERO AUTOBIOGRÁFICO EN HISPANOAMÉRICA}

En los estudios sobre la autobiografía hay un vacío que convoca la pregunta acerca de la existencia de una tradición autobiográfica hispanoamericana que, aunque desvinculada de tradiciones como la inglesa, sin duda da cabida a textos cuya construcción se asemeja al proyecto introspectivo y confesional con que nace el género. ¿A qué se debe la escasez de autobiografías en Hispanoamérica? Hay quienes arguyen que se trata de una actitud lectora, es decir, que las autobiografías hispanoamericanas no han sido leídas como tales, en parte porque al no estar restringidas por clasificaciones genéricas estrictas, han tenido mayor libertad para revelar sus contradicciones y su hibridez (Molloy, 1996: 12). Aunque abundan las narraciones en primera persona desde la Conquista y la Colonia, la pregunta por el "yo" ha ido casi siempre acompañada por una finalidad testimonial. Las condiciones históricas y culturales de nuestros países han moldeado esa veta autobiográfica de tal manera que el interés por el yo se ha circunscrito a las preocupaciones de índole ideológica o social.

A decir de Sylvia Molloy, la preocupación nacional y la conciencia cultural, aunadas a la autocensura, a la vacilación entre lo público y lo privado, son sólo algunas de las inquietudes que priman en la autorrepresentación del autobiógrafo hispanoamericano (1996: 15). Por eso, el espacio para la exploración del "yo" del autor está sujeto a intereses que tienen más que ver con la creación de una imagen pública y con el "imperativo documental" (1996: 18). En efecto, los afanes de afianzar una identidad nacional, de defender la autonomía política y cultural, y la necesidad de conceder un espacio crítico a fenómenos sociales de diversa índole han influido en anteponer los deberes patrióticos a la pulsión narcisista de expresar asuntos más personales. No es casualidad, por las mismas razones, el arraigo de la imagen del escritor comprometido, tan característica de América Latina, pues el entorno y las circunstancias históricas son los factores que han definido y moldeado la manifestación soterrada de un sujeto interesado en sí mismo en tanto engranaje de la maquinaria social. ${ }^{1}$ Se cree también

\footnotetext{
1 Jorge Ruffinelli sugiere que el hueco en la práctica autobiográfica entre los escritores hispanoamericanos se debe, entre otras razones, a la "azarosa formación de las culturas nacionales hispanoamericanas, y por ende la carencia de una tradición amplia dentro de la cual insertar la experiencia personal; sin duda gravita la imbricación de la escritura con la historia social y política de América Latina, que deja de lado al individuo ante las urgencias colectivas" (1986: 513).
} 
que esa suerte de recelo por la exhibición de lo personal es una marca cultural del mundo hispánico determinada por los preceptos de la religión católica, que favorece la vida y el comportamiento públicos sin dejar lugar a la intimidad y para la expresión de las preocupaciones personales, a diferencia de los países protestantes, donde el individualismo surge tempranamente al lado de la conciencia de sí, valores estos característicos de la sociedad moderna y capitalista (Molino, 1991: 130-131). ${ }^{2}$

Si bien a principios del siglo xx se gestan ya algunas autobiografías, como la de Rubén Darío, La vida de Rubén Darío escrita por él mismo (1915), o el Ulises Criollo y los volúmenes que le siguieron (1935-1939), de José Vasconcelos, será hasta los años sesenta y setenta cuando se pueden contar algunos libros decididamente autobiográficos, aunque algunos de ellos prefieran optar por la etiqueta de "memorias", apegados aún al análisis de la circunstancia externa y no a la exploración interior que caracteriza a la autobiografía. Entre otros, se encuentran las Memorias de Jaime Torres Bodet publicadas en dos volúmenes entre 1969 y 1971; la autobiografía de Manuel Maples Arce, A la orilla de este río (1964); de Pablo Neruda, Confieso que he vivido (1974); y el libro de memorias de Jorge Edwards, Persona non grata (1973). Es notable, asimismo, la colección "Nuevos escritores mexicanos del siglo xx presentados por sí mismos", resultado del proyecto de publicación de autobiografías de escritores jóvenes emprendido por Emmanuel Carballo y Rafael Giménez Siles en la década de 1960. Tan solo en 1966, como resultado de este proyecto, salieron a la luz las autobiografías de Salvador Elizondo, José Agustín, Juan Vicente Melo y Juan García Ponce, que años más tarde serían seguidas por las de Gustavo Sáinz, Sergio Pitol, Carlos Monsiváis, entre otros. A pesar de la magnitud del esfuerzo por impulsar el género, la relativa juventud de algunos de estos escritores al momento de emprender la evocación de experiencias, dio como resultado tentativas que, por rutas distintas, se alejan de lo que en principio requiere la escritura de una autobiografía.

2 En relación con la autobiografía argentina, Noé Jitrik considera, lo mismo que Adolfo Prieto, que las evocaciones de esas autobiografías (de principios del siglo xix y parte del $\mathrm{xx}$ ) están orientadas a exaltar los valores de la oligarquía e impregnadas de una marcada historicidad: "revoluciones (de Mayo, del 90), guerras de independencia y civiles, rosismos, mitrismos, el ochenta, la inmigración y la organización del país moderno, constituyen los ejes de los relatos, en torno de los cuales la inflexiones subjetivas son como tenues bordados, apagados traumas, repliegues de lo individual en homenaje a la trascendencia" (1998: 75-76). 
Es hasta finales de la década de 1970 cuando la publicación de autobiografías y memorias - algunas póstumas- comienza a hacerse más profusa. Sólo por mencionar algunos ejemplos, la autobiografía de Victoria Ocampo se publica en seis partes entre 1979 y 1984; en 1983 sale a la luz la Historia personal del Boom de José Donoso; en 1988 el primero de dos libros autobiográficos de Augusto Monterroso, La letra e. Fragmentos de un diario así como las memorias de Nicolás Guillén, En la guerra de España: crónicas y enunciados y Páginas vueltas y la primera parte de las de Bryce Echenique, Crónicas personales (Romera Castillo, 1995). A partir de entonces, el número de autobiografías y memorias ha ido en aumento al mismo tiempo que la narrativa de ficción ha puesto especial énfasis en lo autobiográfico, de modo que bien se puede hablar, con Jean Molino, de la "democratización de la autobiografía", o de un fenómeno de moda, como sugiere Ana Caballé (1995), consecuencia inevitable de la globalización y de la cultura de masas de nuestra sociedad capitalista. En opinión de Noé Jitrik, el gesto autobiográfico de la literatura contemporánea se debe a un cambio en las relaciones entre lo privado y lo público; esto es, un cambio de actitud ante un espacio (el público) ya consolidado, que poco necesita continuar con los esquemas del siglo xIX de "exposición de una circunstancia histórica, justificación de un comportamiento, rectificación de errores y exculpación de responsabilidades" (1998: 77).

Hay, por lo demás, un vacío crítico y teórico en torno a la autobiografía de nuestras latitudes, que puede deberse a la relativa juventud del género como tal, ya que es hasta el siglo $\mathrm{xx}$, y sobre todo a partir de su segunda mitad, cuando, al lado de memorias, diarios y novelas autobiográficas, se despierta cierto interés por la escritura de autobiografías. Hay pocos títulos que vale la pena mencionar, entre ellos: los estudios de Adolfo Prieto, La literatura autobiográfica argentina (1966); Nicolás Rosa, El arte del olvido: sobre la autobiografía (1990); Nora Catelli, El espacio autobiográfico (1991) y En la era de la intimidad. Seguido de El espacio autobiográfico (2006); Sylvia Molloy, Acto de presencia. La escritura autobiográfica en Hispanoamérica (1991, primera edición en inglés); Leonor Arfuch, El espacio biográfico. Dilemas de la subjetividad contemporánea (2002) y José Amícola, Autobiografía como autofiguración (2007). Estos aportes merecen un comentario aparte, que por cuestiones de espacio, solo limitaré a una rápida acotación sobre los trabajos de Molloy, Catelli y Arfuch, cuyo rigor en el tratamiento del tema ofrece conclusiones fructíferas. Una de ellas - la que establece 
un punto de contacto entre las tres posturas y puede verse como la forma particular de concebir el fenómeno autobiográfico hispanoamericano desde la década del sesenta- es la de pensar al yo en su relación con las circunstancias sociales e históricas.

El libro de Molloy no se dedica propiamente a la reflexión teórica, sin embargo, entronca los presupuestos del género autobiográfico con las características particulares de las autobiografías hispanoamericanas para deducir las formas en que el "yo" lleva a cabo la figuración o figuraciones de sí. Su propuesta persigue desentrañar los vínculos entre la autofiguración, la identidad nacional y la conciencia cultural (1996: 15) en tanto elementos constitutivos de la autobiografía hispanoamericana: "ver esa preocupación nacional como espacio crítico, marcado por una ansiedad de orígenes y de representación, dentro del cual el "yo" pone en escena su presencia y logra efímera unidad" (Molloy, 1996: 14-15). La de Arfuch es una postura muy parecida a la de Molloy, aunque desde un enfoque distinto: si para Molloy el yo pergeñaba su autofiguración atendiendo a la circunstancia nacional (social, política, etc.), Arfuch considera la inteligibilidad del sujeto contemporáneo, la constitución de la identidad y, por lo tanto, el desarrollo de la autobiografía (y todas las formas autobiográficas de la escritura), desde un espacio dialógico (Bajtín), intersubjetivo, donde la individualidad necesita entenderse a partir de su inscripción en lo social. Lo que Arfuch denomina, en un guiño a Lejeune, el "espacio biográfico" - en el que se desenvuelven los relatos cuya finalidad es, en el sentido más general, narrar una vida - sería un espacio intermedio entre lo público y lo privado. A su vez, Catelli, en En la era de la intimidad, retoma el tópico que en principio inquietó a Arfuch: la urgencia del sujeto contemporáneo de mostrarse públicamente, de exteriorizar su experiencia, su intimidad, por un lado, y la demanda social de lo real, lo verdadero, por el otro. Exigencias que han entrado siempre en tensión con el lenguaje y la escritura debido a la imposibilidad que supone asir ese sujeto y reconstruir su experiencia; sin embargo, lo íntimo está ahí pugnando por ejercer su derecho al reconocimiento social. Para Catelli la intimidad es, como el espacio biográfico de Arfuch, no un lugar de oposición sino de comunicación entre lo público y lo privado, y por consiguiente, un instrumento para interpretar los acontecimientos históricos, es decir, un modo de colocar la autobiografía en la historia.

En los años previos al nacimiento de la autoficción se genera la crisis de la autobiografía, muy a tono con la crisis del sujeto moderno, que oscila 
entre su desaparición y su retorno en el ámbito discursivo. Con el paso del tiempo la autobiografía se nutre de las técnicas narrativas de la novela e, incluso, asume como suyo el elemento ficción, al mismo tiempo que la novela se vuelca cada vez más sobre el "yo" autobiográfico. Tan es así, asegura Molino, que un rasgo importante de la narrativa contemporánea es el descubrimiento del "realismo subjetivo", mediante el cual se pretende dar cuenta de los contenidos de la conciencia y del mundo desde la perspectiva del sujeto (1991: 134). Esto se relaciona con la idea de que lo autobiográfico llegó para renovar los agotados esquemas de la narrativa de ficción al aportarle el sello de lo personal, ese "sinceramiento en cuyo despliegue la noción de cercanía con lo que se narra [...] parece ser la única y verdadera salida" (Jitrik, 1998: 80). Dicho intercambio ha terminado por anular las fronteras entre los géneros hasta el punto que se ha llegado a creer que la autobiografía ya no existe, y lo único que la distingue es "la relación exterior del texto con el sistema de creencias del lector" (Molino, 1991: 134). De cualquier modo, las décadas de 1960 y 1970 vieron nacer relatos que incluían al autor ya como protagonista o como presencia esporádica -mediante el uso del pronombre "yo" o del nombre propio. Son estos años los que marcarán el comienzo de nuevas formas de realizar autobiografías, que se apreciarán en el abandono de los escritores a hablar de ellos mismos tanto en autobiografías, diarios íntimos y memorias como en novelas autobiográficas y autoficciones. Estas últimas son quizá el artefacto literario más extraño, vistas aún con escepticismo y hasta con rechazo, pero son también formas alternativas de tratar los textos que más se han aventurado a la exploración del "yo" del autor y a la ruptura e hibridación genéricas.

La conflictiva percepción del sujeto contemporáneo generó también la discusión teórica en torno a la autobiografía tanto para tratar de definirla como género y delimitar sus fronteras, como para cuestionar su capacidad de representar al "yo" del autor y trazar la trayectoria de su vida. En todo caso, como advierte Jitrik, aunque los procedimientos selectivos de la autobiografía la acerquen a la ficción, el trato del elemento ficcional es distinto en cada género: en la autobiografía queda al descubierto el proceso de enunciación al reducir la distancia con el autor, esto es, al confundir el yo narrador con el yo narrado (1998: 79). La transición a estadios de exploración personal, autoconocimiento y autoanálisis se da de manera abrupta a mediados del siglo pasado, cuando la homogenización cultural convocó a la libre expresión y a la liberación de ataduras sociales mediante 
movimientos que dieron voz a sectores oprimidos (mujeres, homosexuales y otros grupos subalternos). De este modo, se da un salto cualitativo marcado por un cambio de enfoque: los escritores se vuelcan sobre sí mismos preocupados más por su ser en la escritura y en la cultura que por interpretar la historia o justificar su actuación dentro de ella.

\section{DE LA AUTOBIOGRAFÍA A LA AUTOFICCIÓN: UN TRÁNSITO INCOMPLETO}

Ese contexto de rupturas será el origen, en la década de 1970, del replanteamiento de los problemas que proyecta la autobiografía en relación con la pretendida búsqueda de identidad de un sujeto que se sabe disgregado y cuyo autoconocimiento tendrá que enfrentar utilizando medios igualmente diversos; otros géneros y técnicas narrativas se convertirán en apoyo de una escritura que necesita dar cuenta de una experiencia vital enriquecida por la perspectiva puesta en la realidad interior del individuo. La autoficción representa uno de esos replanteamientos, quizás el extremo que la autobiografía ha estado rozando todo el tiempo, el de la ficción. A partir de los postulados de la autoficción muy posiblemente se haya puesto un alto temporal al estiramiento de la autobiografía hacia ese otro extremo; y digo temporal porque las dificultades surgidas alrededor del yo no son pocas, y porque la autoficción misma no ha terminado de constituirse como género literario. Con todo, al ocuparse del yo desde muy diversos ángulos y con plena libertad, la autoficción parece delegar nuevamente el problema de la referencia a autobiógrafos y estudiosos de la autobiografía, pues sugiere otras formas posibles de enfrentar el estudio de la entidad compleja que es el yo autoral.

En ese mismo periodo se cocinaron los valores y las ideologías que a partir de 1980 generarían un repliegue de los relatos hacia lo íntimo y lo privado. La vuelta del sujeto derivaría, como advierte Leonor Arfuch, en la invasión del espacio público por lo privado, por relatos en los que el yo ocupa el primer plano al lado de aspectos del mismo modo relacionados con la esfera de lo personal, pero también en la incorporación del factor referencial, relativo a la narración de una vida, en el espacio literario: el abandono de la narración omnisciente en favor de la primera persona, el relato de lo cotidiano, la democratización de la palabra, es decir, la inclusión de las voces de minorías, así como la exaltación del cuerpo y la sexualidad: 
la subjetividad que ponía en juego los relatos venía por lo general "atestiguada" por la asunción del "yo", por la insistencia en las "vidas reales", por la autenticidad de las historias en voz de sus protagonistas, ya sea en el uso directo de las cámaras o en la inscripción de la palabra gráfica, por la veracidad que el testimonio imponía al terreno resbaladizo de la ficción (2010: 21).

En la persecución de dicha autenticidad, la novela, el más híbrido y proteico de los géneros narrativos, abarcó un amplio territorio dentro de lo que Philippe Lejeune denominó el "espacio autobiográfico", lugar de convergencia de las distintas manifestaciones escritas del yo.

El surgimiento de la autoficción se explica mejor si se tiene en cuenta, por un lado, esta atmósfera de tensión de la autobiografía - o como apunta José María Pozuelo Yvancos, de la "deconstrucción del yo autobiográfico"- y la ampliación de las dimensiones autobiográficas de la novela; y por el otro, la "crisis del personaje como entidad narrativa" postulada por los escritores del Nouveau Roman (Yvancos, 2012: 154-156). Dos años antes de que, en 1977, Serge Doubrovsky propusiera el término "autoficción" para calificar a su novella Fils, Roland Barthes había concebido un texto de similar factura, que ponía en tela de juicio el valor representativo de la autobiografía al negar su propia condición autobiográfica en favor de la ficcionalidad; es decir, al puntualizar que lo dicho por él, por el Roland Barthes del libro, debía considerarse como "dicho por un personaje de novela", pero sobre todo por hacer de ese personaje una entidad que planteaba la descomposición y el desmoronamiento de su identidad. Con el rechazo de toda relación con un referente, tanto en la ruptura de la narración tradicional como en la negación de sí mismo como objeto de su escritura, Barthes apuesta a conseguir lo que algunos llamarían una anti-autobiografía, o lo que Doubrovsky denominaría autoficción.

En el ámbito de la teoría, la autoficción nace, sin proponérselo, como respuesta al "Pacto autobiográfico" (1975), donde Philippe Lejeune formula un cuadro para clasificar los distintos casos de la autobiografía en relación, por una parte, con la identidad nominal entre personaje y autor (ya sea que haya identidad, que el personaje use nombre diferente o no tenga nombre), y por la otra, con el pacto de lectura establecido en la portada del libro o en alguna de sus páginas (autobiográfico, novelesco o pacto cero) (1991: 54). Lejeune nombra a una de las casillas de su esquema "los casos ciegos", y en ella incluye dos posibilidades: que en una novela el héroe tenga el mismo nombre que el autor — caso, para Lejeune, posible 
pero del que no tiene un ejemplo a la mano-y que en una autobiografía declarada no haya identidad nominal —situación imposible, incluso como efecto artístico. Ante estos dos escenarios, Lejeune advierte que

si la contradicción interna fue elegida voluntariamente por el autor, el texto que resulta no es leído ni como autobiografía ni tampoco como novela, sino que aparece como un juego de ambigüedad pirandeliana. A mi entender es un juego al que no se juega con intenciones serias (1991: 55).

La invención terminológica de Doubrovsky llegó para llamar la atención, no sobre el nacimiento de un nuevo género, sino más bien sobre la existencia de textos que desde antaño han mostrado, de maneras diversas, al autor, pero especialmente sobre las dificultades de la autobiografía y de la novela autobiográfica para abarcar las posibilidades que ofrece el yo en la literatura contemporánea, así como para sugerir el replanteamiento de los conceptos de autor y autoría.

Los estudios sobre la autoficción han proliferado de manera espectacular desde 1980, sobre todo en Francia, donde se han llevado a cabo congresos y compilaciones de artículos dedicados tanto a la literatura como a otras artes (el cine, la fotografía y la pintura). El mundo hispánico cuenta ya también con algunos estudios, tesis y congresos, el último de los cuales se llevó a cabo en la Universidad de Bremen en 2009 y dio como resultado el volumen compilado por Vera Toro, Sabine Schlickers y Ana Luengo, La obsesión del yo. La auto(r)ficción en la literatura española y latinoamericana (2010), donde por primera vez se incluye a Latinoamérica. ${ }^{3}$ La teoría se ha divido hasta el punto en que hoy en día, a pesar de que el término se ha extendido por doquier y se lo usa corrientemente, no hay un consenso ni se ha terminado de establecer como género literario o artístico. Al principio estuvo apegada a sus orígenes autobiográficos; sin embargo, pocos años después ganó terreno en la novela, destino casi predecible si se tienen en cuenta las dificultades, ya mencionadas, de la autobiografía para representar al yo y la riqueza de posibilidades de la novela para asumir ese papel. De cualquier modo, las opiniones siguen fluctuando entre estos dos polos. Doubrovsky mismo, en un artículo de 2003, declara aún que la autoficción es "una variante posmoderna de la autobiografía", afirmación que Philippe Gasparini retoma casi al pie de la letra en Autofiction. Une aventure du langage (2008) cuando considera

3 Para un repaso completo de la historia y los problemas de la autoficción véase el artículo de Ana Casas, "El simulacro del yo: la autoficción en la narrativa actual", que sirve de introducción a su compilación La autoficción. Reflexiones teóricas (2012). 
que se trata de una forma contemporánea de la autobiografía. Al parecer la segunda vertiente, orientada hacia la novela, ha ganado más adeptos, entre ellos Marie Darrieusecq, Vincent Colonna, Philippe Vilain y, desde el ámbito hispánico, Manuel Alberca. ${ }^{4}$ La noción de "pacto ambiguo" de este último intenta una solución que invita a hacer una lectura simultánea de dos géneros y establecer dos pactos, el autobiográfico y el novelesco, con lo que se ostenta lo contradictorio y paradójico, de esta forma de escritura.

Si bien la autoficción viene a retomar el problema del autor en el momento en que a la autobiografía parece escapársele, las soluciones que hasta ahora propone son aún un tanto limitadas, pues seguimos preguntándonos: si este tipo de textos no se limita a la relación vida-literatura, herencia de la autobiografía ¿qué tipo de relaciones destacan con el referente, con lo real?, ¿qué noción de autor implican y qué aportan a su conocimiento en relación con la escritura? En todo caso, la autoficción sugiere problemas más complejos y estimulantes que su determinación genérica: la concepción de autor y autoría, las figuraciones del yo del autor y, una de sus consecuencias, la creación de figuras de autor, ficciones de autor o autoficciones - en el sentido que Julio Premat atribuye al término-, así como los alcances estructurales de la presencia del autor en el libro, entre otros. $^{5}$

\footnotetext{
4 Entre otros, destacan Marie Darrieusecq, quien en su primer artículo, "Je de fiction" (1997), sitúa la autoficción del lado de la autobiografía, aunque posteriormente asuma una posición intermedia. Por su parte, Vincent Colonna (1989) define la autoficción como "une cuvre littéraire par laquelle un écrivain s'invente une personalité et une existence, tout en conservant son identité réell (son veritable nom)" (34). En su libro L'Autofiction en théorie suivi de deux entretiens avec Philippe Sollers \& Philippe Lejeune (2009), Philippe Vilain la considera como "[f]iction homonymique qu'un individu fait de sa vie ou d'une partie de celle-ci" (57). En opinión de Manuel Alberca, la autoficción es "una novela o relato que se presenta como ficticio, cuyo narrador y protagonista tienen el mismo nombre que el autor" (2007: 158).

5 Con su concepto de "figuraciones del yo", José María Pozuelo Yvancos esclarece las limitaciones de los críticos que relacionan la autoficción casi exclusivamente con lo biográfico y restringen la representación del "yo" a la gastada relación texto-vida. Coincido en que es preciso superar esa relación, pues la autoficción no se reduce a esa categoría ni abarca todas las posibilidades de figuración del yo en la literatura; dicho de otro modo, no todos los textos en los que participa el autor son autoficciones, ni toda autoficción se funda en los vínculos con lo autobiográfico por más que éste haya sido su origen conceptual. "[L]a figuración de un yo personal puede adoptar formas de representación distintas a la referencialidad biográfica o existencial, aunque adopte retóricamente algunos protocolos de esta (por semejanzas o asimilaciones que puedan hacerse de la presencia del autor)
} 
Ahora bien, el problema de la presencia del autor puede enfrentarse desde las condiciones de un espacio autobiográfico que dé cabida a las complejidades del referente y estipule, con fines pragmáticos, ciertas expectativas en relación con la operatividad de los géneros. Por eso ha sido necesario esbozar algunos rasgos de la autoficción provenientes tanto de la autobiografía como de la novela que puedan servir en un momento dado para describir un texto de esta naturaleza. Isabel de Castro considera que la inclinación de la novela contemporánea hacia lo autobiográfico encuentra tres vías de expresión: primero, en cuanto al tema, hay una recurrencia a la indagación personal; segundo, se favorece la presencia del personaje escritor como protagonista consciente de llevar a cabo un trabajo escrito; y tercero, hay cierta predilección por la narración en primera persona y el uso de otras formas autobiográficas de escritura como diarios, memorias o cartas (1993: 155-156). La autoficción hace suyas estas formas de expresión y las lleva a sus últimas consecuencias, y lo hace recurriendo especialmente a un elemento clave en la autobiografía: el nombre del autor, del cual depende, en gran medida, el establecimiento del pacto autobiográfico.

El nombre propio representa la entrada triunfal del autor, es el primer indicador de la identidad autor-narrador-protagonista (para los relatos en primera persona) o autor-protagonista (para los relatos en tercera persona), así como de la tensión adentro-afuera, realidad-ficción, característica de este tipo de relatos. La identidad inducida por el uso del nombre, uno de los elementos primordiales de la autobiografía según la definición de Lejeune, anima una lectura autobiográfica, aunque el contenido autobiográfico esté falseado o no exista en absoluto. La presencia del nombre del autor, lo mismo que los nombres de personajes históricos o lugares, inevitablemente se convierte en un campo magnético que atrae significaciones provenientes de entidades de otro nivel de realidad. El nombre real, en opinión de Lejeune, "comunica a todo lo que toca un aura de verdad [...] y todo lo que se dice de él, incluso dado por ficticio, se incluye en su definición" (1994: 186). El uso de nombres propios que designan a personas reales, a decir de Lejeune, tiene efectos independientes de las indicaciones genéricas, pues

(2012: 161)". Por su parte, Premat concibe la "ficción de autor" o autoficción como la construcción de una imagen de sí mismo que el autor emprende en una o varias de sus obras y que junto con la imagen pública conocida por otros medios, constituye lo que se ha dado en llamar "figura de autor", esto es, la caracterización discursiva del autor y un modo de ser en la sociedad. 
estas no garantiza que el lector pueda leer el enunciado únicamente como ficción: "considerará más bien la aserción como juego, hipótesis, figura, concerniente a la persona real" (1994: 186). Otro tipo de información precisa, como las iniciales, pseudónimos conocidos, nombres de otras obras del autor, etc., puede tener un valor similar al nombre propio al momento de establecer la identificación del narrador o del personaje con el autor.

El tipo de narración es otro de los rasgos distintivos: aunque la narración en tercera persona es igualmente válida, se privilegia la primera persona y, con ella, las técnicas y recursos que recuperen la inmediatez del discurso, es decir, las formas más eficaces para acercarse al yo, para profundizar en él y crear un "efecto de realidad". Por eso la oralidad, la narración interior, el empleo de otros géneros y discursos, como cartas, diarios, ensayos, fotografías, refuerzan la proximidad del mundo de la ficción con lo externo, aunque, paradójicamente, exponen la artificialidad del relato y derivan en procedimientos metaficcionales como la metalepsis, el autocomentario y la mise en abyme, que a su vez se relacionan con el carácter híbrido de estos textos. Se consideran, además, otras características como "la intensificación de la manipulación del orden cronológico" y la "alternancia de voces y los cambios de focalización” (Ana Casas, 2010: 194), vinculados con la experimentación y la búsqueda de una forma original. ${ }^{6}$ Estos elementos forman parte de los procedimientos explotados por la novela moderna, de ningún modo son exclusivos de la autoficción; lo que ésta hace es que, mediante la incorporación del autor y el ahondamiento en el yo, los lleva hasta sus últimas consecuencias, maximiza sus efectos y se vuelve así una forma de escritura mucho más experimental que otras.

Sin duda, hay aún mucho que decir. Baste por ahora con advertir que, amén de las características que se le atribuyan, hay dos elementos fundamentales, en mi opinión, inseparables de la autoficción: la exhibición del autor y su protagonismo. A diferencia de la novela autobiográfica, que se funda en el principio de ocultación y sólo da pistas para sospechar la presencia oculta del autor, la autoficción busca mostrarlo sin miramientos, a veces en los aspectos más bajos y hasta ridículos de su persona, ya que, escudados tras las prerrogativas de la ficción, su valor de verdad no entra en juego. El impulso narcisista lleva al autor a proyectarse con todas sus limitaciones

6 Philippe Gasparini deduce los siguientes criterios para clasificar la autoficción: oralidad, innovación formal, complejidad narrativa, fragmentación, alteridad, contraste y autocomentario (2008: 209). 
hasta el punto en que, por esta vía, favorece su heroización y la creación de una figura que, muchas veces, consigue la mitificación, aunque, contradictoriamente, una de las notas que la autoficción intensifica es, a decir de Pilar Andrade, la imagen del antihéroe, del héroe del absurdo, escéptico y existencialista (1993: 87). ${ }^{7}$ Imagen que se construye, precisamente, a partir del ser escritor, de las lecturas y experiencias que han moldeado su relación con la escritura-literatura. Por eso, al recuperar el tema de la presencia del autor en el libro y el comentario alusivo ya sea al mismo acto de escritura, al cuestionamiento del trabajo del escritor o a reflexiones literarias, el relato autoficcional complejiza los procedimientos narrativos más socorridos por la novela contemporánea.

\section{AUTOFICCIONES HISPANOAMERICANAS}

Por las mismas fechas en que se origina el debate sobre la autoficción, en la literatura hispanoamericana se producen obras en las que al mismo tiempo que se apuesta a conceder cierto protagonismo al autor convertido en personaje de su propia ficción, se problematiza el concepto de autor y su relación con la escritura. Más allá de su construcción novelística, estos textos impusieron un nuevo estatus a las dimensiones autobiográficas inscritas en ellos mediante la instauración de un espacio ocupado por el autor, espacio que no única ni necesariamente era el autobiográfico. La naciente propensión a jugar con los límites entre lo real y lo imaginado, entre géneros que convocan materiales e intencionalidades distintas, superó con mucho la crisis ficcional de la autobiografía en la medida en que la ficción narrativa no sólo se apropió de esa entidad denominada "autor" sino que además amplió las posibilidades de su conocimiento al ponerla en relación con eso que lo constituye como tal: la escritura. Así lo muestran los experimentos de Roland Barthes y Serge Doubrovsky, pese a que la discusión alrededor de su empresa siga centrándose casi exclusivamente en su aspecto autobiográfico.

Conviene puntualizar aquí, aunque con brevedad, el hecho de que en paralelo al desarrollo de la autoficción en Francia se da en Hispanoamérica el despliegue de la reflexión en torno al relato testimonial, el cual

7 Andrade observa que "la manera de esforzarse del héroe autobiográfico del absurdo es escribiendo: sólo así puede salvar su propia paradoja substancial, en efecto, pero la consecuencia directa de ello es su identificación con el autor" (1993: 91). 
se acercó, por otros senderos, a los mismos problemas planteados por la autoficción: la relación realidad-ficción, la incorporación de la experiencia del autor, el rompimiento y mezcla de los géneros (Rincón, 1978) ${ }^{8}$ El uso del testimonio obedeció a los cambios operados en las esferas social, política y cultural de nuestros países alrededor de esos años, así como a la necesidad de liberarse de los modelos artísticos de la ideología burguesa individualista importada de Europa (Jameson, 1992). Fredric Jameson destaca el valor del testimonio, a partir de la reconsideración del dialogismo bajtiniano, en el viraje que se produce dentro del discurso literario latinoamericano en la segunda mitad del siglo $\mathrm{xx}$, viraje relacionado con la despersonalización y la pérdida de autoridad, pero no en el sentido de la muerte del autor, sino como la construcción de "un nuevo espacio colectivo entre sujetos conocidos y seres humanos individuales", así como con el anonimato, entendido no como la pérdida del nombre, sino como la multiplicación nombres e identidades (130-131). ${ }^{9}$ Por su parte, Mónica Quijano observa el carácter autoficcional que pueden tener algunos relatos testimoniales, en concreto las prácticas en que la memoria individual está atravesada por la memoria colectiva (familiar, comunitaria) y sirven de expresión a la voz de los otros (polifonía). En este sentido, considera los relatos de escritores tocados por la experiencia del exilio, en los que la reconstrucción de la memoria familiar exige el recurso al testimonio y a la historia oral, narrativas híbridas que confunden la voz del autor con otras tantas voces y la búsqueda de la identidad personal es posible solo mediante el recuento de la historia de la comunidad. Las genealogías (1981) de Margo Glantz y Los rojos de ultramar (2005) de Jordi Soler, a los

8 Características todas que Carlos Rincón percibe en El Cimarrón (1967) de Miguel Barnet, obra sintetizadora de las distintas rutas seguidas por la nueva novela latinoamericana y en la que "[1] as especificidades normativistas de lo que sería la biografía y la autobiografía, la novela y las memorias, las tareas del editor y el trabajo del autor, lo propio de las ciencias sociales y el arte narrativa, y ante todo los límites de lo ficticio y lo no ficticio en el texto, de la realidad relatada y la realidad producida, son abolidas" (30).

9 Entre otros, el estudio de Carlos Rincón, El cambio actual de la noción de literatura y otros estudios de teoría y crítica latinoamericana (1978) - donde propone una aproximación completa y esclarecedora a las vertientes de la teoría y la crítica en Latinoamérica a partir de los años sesenta- y las aportaciones de Fredric Jameson, John Beverly y Margaret Randall (1992) ofrecen algunos acercamientos a la forma y las funciones del testimonio; asimismo, la compilación de Rodrigo García de la Sienra, Mónica Quijano e Irene Fenoglio, La tradición teórico-crítica en América Latina: mapas y perspectivas (2013) rastrea las transformaciones históricas, políticas, culturales y literarias de América Latina enmarcadas en las últimas cuatro décadas. 
que añadiría Las hojas muertas (1984) de Bárbara Jacobs, son ejemplos de este tipo de narrativas que proponen "un pacto ambiguo entre lo ficcional y lo autobiográfico [...] que lleva al lector a establecer un vínculo referencial mucho más directamente que con otro tipo de relatos fictivos" (Quijano, 2013: 174).

Ya Manuel Alberca (2005-2006; 2007: 301-307) ha dedicado espacio en sus estudios para señalar la existencia, en la literatura hispanoamericana, de novelas semejantes a las autoficciones registradas en otras literaturas, como la francesa o la española. Su lista es extensa e incluye relatos tan tempranos como la novela inconclusa de Rubén Darío, El oro de Mallorca (1913-1914) o De sobremesa (1925) de José Asunción Silva, así como varios cuentos de Borges: "El Aleph", El Aleph (1949), "Borges y yo", El hacedor (1960), "Hombre de la esquina rosada", Historia universal de la infamia (1975), "El otro", El libro de arena (1975), entre otros. Dentro de los libros que se publicaron alrededor de los años en que se inaugura la autoficción se encuentran El hipogeo secreto (1968) de Salvador Elizondo; De dónde son los cantantes (1967) de Severo Sarduy; El Zorro de arriba y el Zorro de abajo (1971) de José María Arguedas; "Homenaje a Roberto Artl”, Nombre falso (1975) de Ricardo Piglia; La tía Julia y el escribidor (1977) de Mario Vargas Llosa; La busca del jardín (1977) de Héctor Bianciotti; y La Habana para infante difunto (1979) de Guillermo Cabrera Infante. ${ }^{10}$

A mi ver, uno de los logros más tempranos sobre esta inquietante exploración se encuentra en El hipogeo secreto, de Salvador Elizondo, ${ }^{11}$ novela cuya complejidad revela la incertidumbre del autor ante la paradoja del sueño y la escritura, mediante los que intenta mostrar la imposibilidad de separar al escritor-soñador-soñado de su sueño-escritura, pues ambos se crean mutuamente en el proceso de la articulación de la palabra escrita. La presencia del nombre del autor, como ocurre en todos los textos autoficcionales, es el detonante del juego de espejos y de la confusión de planos ontológicos sobre los que se construye todo un entramado metatextual. El hipogeo secreto trata sobre un escritor que escribe sobre otro escritor

10 Es hasta la década de los ochenta cuando se comienza a registrar un mayor número de autoficciones. El listado de Alberca incluye otros textos de Ricardo Piglia publicados a partir de esos años, así como varias novelas de César Aira, Fernando Vallejo y Roberto Bolaño, solo por mencionar los nombres que más destacan en esta tendencia.

11 La participación de Elizondo dentro de El hipogeo secreto ha sido analizada como parte de los procedimientos metaficcionales, perspectiva que linda con los terrenos de la autoficción (Quesada Gómez, 2009). 
que sueña que está siendo escrito por el primero, pero también como la historia de "un hombre y una ciudad que nunca han existido" o como "una historia de horror, de tristeza y de magia" (2000: 45). En algún momento, el narrador cede la voz a un personaje que se nombra a sí mismo "yo, Salvador Elizondo", e imagina una escena en la que un hombre, un pseudo-Salvador Elizondo, escribe un libro que se llama El hipogeo secreto, en el que se imagina que está siendo escrito por Salvador Elizondo, quien, a su vez, podría ser "un personaje apócrifo creado por el dios de la literatura" (2000: 50). El narrador y los personajes persisten en su intento por descifrar su origen y su futuro contenido en las páginas de ese cuaderno rojo que al final del libro, Mía lee al revés en espera de encontrar una cajita china "en la que está contenido el mundo" (2000: 163). Descubren por fin al Imaginado, al autor, escribiendo las últimas palabras del libro, que concluye con un asesinato, ¿el del autor por sus propios personajes?, o un suicidio ¿del narrador-autor con sus propias palabras? La incógnita de la creación persiste, del sueño como creación, del despertar como fin y muerte, la vuelta a la realidad donde el origen esencial de la experiencia de escritura queda en el misterio: el encuentro de la "identidad confusa" se aplaza, pues el autor pretende estar en el umbral, en el "ámbito en el cual los personajes y las cosas estén siempre, como en la vida, a punto de dejar de ser lo que están siendo, a punto siempre de cambiar de nombre" (2000: 53).

El autor que Ernesto Sábato introduce en Abaddón el exterminador -que, por cierto, no figura en las listas de Alberca $-{ }^{12}$ es otro logrado ejemplo de participación del autor en su novela y de la hibridez característica de este tipo de escritura, pues además del marcado autobiografismo, destaca la intratextualidad, es decir, el diálogo con el resto de la obra de Sábato, pero también el diálogo con géneros originalmente no ficccionales, como la carta y el ensayo, mediante los cuales el autor se hace doblemente presente no sólo como personaje sino como el "yo pensante" de la escritura ensayística. Sábato se presenta abiertamente, de forma similar a Elizondo, en el acto de escribir un libro que llevará por título Abaddón el exterminador. En esa tarea de contar los contratiempos que le impiden llevar a cabo su proyecto de novela se entretiene en relatar también los

12 A pesar de la riqueza que ofrece Abaddón el exterminador para repensar tanto el concepto de autor como los postulados de la autoficción, la mayor parte de las aproximaciones críticas apuntan apenas lo novedoso y perturbador de la presencia del autor dentro de la novela. 
pormenores de su experiencia con la escritura, de modo que alude a otros de sus libros, a personajes de sus novelas anteriores, a las ideas expresadas en sus ensayos, a la crítica a sus obras, a entrevistas, etc. Mediante este acto de recolección, de cita, de autoplagio, deja implícita la voluntad de asumir su papel de figura pública del mundo intelectual argentino y latinoamericano. Se permite, además, la exploración de otras posibilidades del nombre: algunas veces es Sabato (sin acento), otras S. y otras Ernesto Sabato, como si de ese modo expresara la identidad múltiple y fragmentada del escritor que se busca a sí mismo en sus ficciones. En este sentido, el personaje-autor se debate entre ser el escritor comprometido exigido por sus lectores - representación del lector promedio hispanoamericano-y del hombre corriente que anda por las calles y plazas de Buenos Aires, que asiste a cocteles y fiestas de la clase acomodada bonaerense, que participa en programas televisivos de entretenimiento familiar; figura ambivalente que destaca de manera simultánea la imagen idealizada del escritor contemporáneo y la autocrítica, la autoironía y el rebajamiento del anti-héroe que se muestra a sí mismo como un ser insignificante, de cuya amarga y mediocre condición se salva solo mediante la escritura.

En "Homenaje a Roberto Arlt", de Ricardo Piglia, ${ }^{13}$ la estrategia aparenta ser más sutil, pues el nombre del autor aparece una sola vez, ligado, sin embargo, al narrador en primera persona que reproduce el estilo y la estructura de un informe o de un resumen de notas - aunque, de hecho, admite que utiliza la forma del relato para presentar estas notas- para dar a conocer sus investigaciones sobre un supuesto cuento inédito de Roberto Arlt, del que planea realizar una edición de homenaje. El relato es toda una parodia del discurso de la crítica y, en consecuencia, la voz que asume el narrador es la de un crítico de la literatura, con lo que se destaca también la figura del lector, faceta singular de la formación de todo escritor. En un gesto casi imperceptible, en una nota al pie de página, parte del aparato crítico que sostiene los hallazgos de Ricardo Piglia personaje, se atribuye cierta información consultada a Emilio Renzi, personaje de Piglia, especie de alter ego, que aparece en buena parte de su obra y que, dicho sea de paso, constituye una de sus marcas autoficcionales, pues se

13 Para un acercamiento desde la autoficción véase José Manuel González Álvarez, En los bordes fluidos. Formas híbridas y autoficción en la escritura de Ricardo Piglia (2009), donde se dedica un capítulo al análisis de "Homenaje a Roberto Arlt". Un estudio detallado de la construcción de la figura de autor en la obra de Ricardo Piglia se encuentra en el libro citado de Julio Premat. 
trata de una variante del nombre completo del autor, Ricardo Emilio Piglia Renzi. En "Homenaje a Roberto Arlt", Piglia destaca varias facetas de la autoría: más allá de ser creador y propietario de una obra, un autor es lector $y$, en esa medida, comenta, imita y, en última instancia, se apropia, de lo escrito por otros. De este modo, al imitar otros discursos y estilos, el escritor se convierte en falsificador, en ladrón, en criminal, pero también en detective entregado a la tarea de llevar a cabo una investigación que resulta ser el relato mismo.

En un tenor un tanto distinto se encuentra La tía Julia y el escribidor de Mario Vargas Llosa, ${ }^{14}$ especie de novela de formación en la que la imagen del autor y su relación con la escritura se construyen a partir del rodeo autobiográfico que alude a la iniciación amorosa y sexual del personaje Varguitas con su tía Julia, en paralelo a su iniciación como escritor. La estrategia de Vargas Llosa consiste en atenuar el protagonismo del autor mediante la intercalación de un segundo relato conformado por las historias de Pedro Camacho destinadas a transmitirse como radionovelas. La alternancia de ambos relatos destaca el artificio y la ficcionalidad esencial de la escritura novelística que enmarca la ficcionalización del autor, con la finalidad de desdeñar, en el mismo acto de exhibición, el vínculo autobiográfico. Con una estructura similar a la novela de Vargas Llosa, por poner un último ejemplo, El Zorro de arriba y el Zorro de abajo, de José María Arguedas, incorpora una figura con trazas autobiográficas en el cuerpo de lo que se lee como ficción; sin embargo, la verdadera intromisión del autor se da al margen de la historia principal en los fragmentos del diario de Arguedas, donde prima la explicación y justificación de la novela que leemos, aunque, en este caso, la presencia del autor no es protagónica, pues su participación en la diégesis es nula. Su interpelación directa al lector implica una voluntad de protagonismo al margen de la ficción y, por lo tanto, de credibilidad, pues el diario, como género, conlleva el recuento cotidiano del diálogo interior con la realidad exterior.

No son pocas las novelas hispanoamericanas que, un tanto al margen del debate teórico europeo o como reacción a este, realizaron la hazaña con que Douvrobsky inauguró la discusión sobre la autoficción. Así des-

14 La crítica ha notado sobre todo la preminencia de lo autobiográfico en la novela de Vargas Llosa; sin embargo, pocos se han dado a la tarea de examinar a profundidad este aspecto. Entre otros, destacan los trabajos de José Miguel Oviedo (1977) y Rosemary Geisdorfer Feal (1986), quien la considera como "autobiografía ficcional”. 
plazaron su atención hacia el espacio redescubierto de manifestación y exploración del yo. Aunque la autoficción hace hincapié en su parentesco y su deuda con la autobiografía, no todos los textos en que participa el autor como personaje invitan a una lectura autobiográfica, como ejemplifican El hipogeo secreto, "Homenaje a Roberto Arlt" o, incluso, De dónde son los cantantes de Sarduy, donde la aparición de un personaje llamado "Yo" desencadena su identificación con el autor. Sin embargo, es evidente que no se pueden eludir las consecuencias del pacto referencial impuesto por el nombre, así se trate sólo del cuestionamiento del autor en relación con su naturaleza de origen de la escritura o de la paternidad respecto de su obra. Lo cierto es que, como sugería Lejeune, estos relatos no dejan de formular un "juego", una "hipótesis", una "figura", una ficción en todo caso, concerniente a la persona real.

A pesar de los intentos por acotar los alcances del término autoficción su uso se ha extendido indiscriminadamente a casi todo texto donde aparezca el autor, sin importar si su presencia es solo esporádica o si el libro advierte en la portada que se trata de memorias u otro tipo específico de escritura del "yo", lo que ha ocasionado que se ponga en duda su validez y funcionalidad. Con todo, al hacer suya la actitud introspectiva de retorno al "yo" - que la novela contemporánea asimila de la autobiografía- la autoficción aporta nuevas perspectivas al estudio de las manifestaciones escritas del "yo" autoral y proporciona los parámetros con los cuales se puede proceder a la búsqueda de las formas de autofiguración exploradas por la novela hispanoamericana aventurada a la empresa de incorporar al autor en su universo de lenguaje e invención.

\section{BIBLIOGRAFÍA}

ALBERCA, M. (2005-2006); “Existe la autoficción hispanoamericana?, Cuadernos del CILHA, 7/8, pp. 115-127. Disponible en http://ffyl.uncu.edu.ar/ IMG/pdf/Alberca-3.pdf Consultado el 8 de agosto de 2014.

(2007); El pacto ambiguo. De la novela autobiográfica a la autoficción. Madrid: Biblioteca Nueva.

ANDRADE, P. (1993); "Aporías autobiográficas", en José Romera, Alicia Yllera, Mario-García Page y Rosa Calvet (eds.), Escritura autobiográfica. Madrid: Visor Libros, pp. 87-92.

ARFUCH, L. (2010); El espacio biográfico. Dilemas de la subjetividad contemporánea. Buenos Aires: Fondo de Cultura Económica. 
CABALLÉ, A. (1995); Narcisos de tinta. Ensayo sobre la literatura autobiográfica en lengua castellana (siglo XIX y XX). Madrid: Megazul.

CASAS, A. (2010); "La construcción del discurso autoficcional: procedimientos y estrategias", en Vera Toro, Sabine Schlickers y Ana Luengo (eds.), La obsesión del yo. La autor(r)ficción en la literatura española y latinoamericana. Madrid: Iberoamericana-Vervuert, pp. 193-211.

(2012); "El simulacro del yo: la autoficción en la narrativa actual", en Ana Casas (comp.), La autoficción. Reflexiones teóricas. Madrid: Arco / Libros, pp. 9-42.

CASTRO, I. de (1993); "Novela actual y ficción autobiográfica”, en José Romera Castillo, Alicia Yllera, Mario García-Page y Rosa Calvet (eds.), Escritura autobiográfica. Madrid: Visor Libros, pp. 153-158.

CATELLI, N. (2006); En la era de la intimidad. Seguido de El espacio autobiográfico. Rosario: Beatriz Viterbo Editora.

COLONNA, V. (1989); L’Autofiction. Essai sur la fictionalization de soi en littérature, Tesis Doctoral, t. I, E. H. E. S. S.

DARRIEUSECQ, M. (1997); “Je de fiction”, en Le Monde, 27 de enero. , (2012); "La autoficción, un género poco serio", en Ana Casas (comp.), La autoficción. Reflexiones teóricas. Madrid: Arco Libros.

DOUBROVSKY, S. (1977); Fils. París: Galilé. , (2003); "Pourquoi l'autofiction", en Le Monde, 29 de abril.

ELIZONDO, S. (2000); El hipogeo secreto. México: Fondo de Cultura Económica. (Letras mexicanas, 122).

GARCÍA DE LA SIENRA, R., QUIJANO, M. y FENOGLIO, I. (cords.). (2013); La tradición teórico-crítica en América Latina: mapas y perspectivas. México: Bonilla Artigas Editores (Colección Heterotopías).

FEAL, R. G. (1986); Novel Lives: The Fictional Autobiographies of Guillermo Cabrera Infante and Mario Vargas Llosa. Valencia: Department of Romance Languages. The University of North Carolina at Chapel Hill.

GASPARINI, P. (2008); Autofiction. Une aventure du langage. París: Éditions du Seuil.

GONZÁlEZ ÁLVAREZ, J. M. (2009); En los bordes fluidos. Formas híbridas y autoficción en la escritura de Ricardo Piglia. Berna/Berlín: Peter Lang AG.

JAMESON, F. (1992); “De la sustitución de importaciones literarias y culturales en el Tercer Mundo: el caso del testimonio". Revista de Crítica Literaria Latinoamericana, 18, 36, pp. 119-135.

JITRIK, N. (1997); “Autobiografías, memorias, diarios”, en Noé Jitrik, El ejemplo de la familia. Ensayos y trabajos sobre literatura argentina. Buenos Aires: Eudeba, Facultad de Filosofía y Letras, Universidad de Buenos Aires. 
MOLINO, J. (1991); “Interpretar la autobiografía”, en Université de Lausanne, Departamento de Español, La autobiografía en lengua española en el siglo veinte. Lausanne: Sociedad Suiza de Estudios Hispánicos, pp. 107-137. (Hispanica helvetica, 1).

MOLLOY, S. (1996); Acto de presencia. La escritura autobiográfica en Hispanoamérica, trad. de José Esteban Calderón. México: El Colegio de México-Fondo de Cultura Económica. (Tierra firme).

LEJEUNE, P. (1991); "El pacto autobiográfico", en Suplementos Anthropos, 29, pp. 47-61.

(1994); El pacto autobiográfico y otros estudios, trad. de Ana Torrent. Madrid: Megazul-Endymion.

OVIEDO, J. M. (1977); “La tía Julia y el escribidor o el autorretrato en clave”. Espiral Revista, 3, pp. 285-310.

POZUELO YVANCOS, J. M. (2012); “"Figuración del yo» frente a autoficción”, en Ana Casas (comp.), La autoficción. Reflexiones teóricas. Madrid: Arco Libros, pp. 151-173.

PREMAT, J. (2009). Héroes sin atributos. Figuras de autor en la literatura argentina. Buenos Aires: Fondo de Cultura Económica.

QUESADA GÓMEZ, C. (2009); La metanovela hispanoamericana en el último tercio del siglo XX. Las prácticas metanovelescas de Salvador Elizondo, Severo Sarduy, José Donoso y Ricardo Piglia. Madrid: Arco Libros.

RINCÓN, C. (1978); El cambio actual de la noción de literatura y otros estudios de teoría y crítica latinoamericana. S/l: Subdirección de Comunicaciones Culturales. División de Publicaciones.

ROMERA CASTILLO, J. (1995); “Escritura autobiográfica hispanoamericana aparecida en España en los últimos años”, en Ferrán Carbó et al., (eds.), Homenatge a Amelia García-Valdecasas, t. II. Valencia: Universitat de València-Facultat de Filología, pp. 727-740.

RUFFINELLI, J. (1986); “Al margen de la ficción: autobiografía y literatura mexicana", Hispania, 69,3, (septiembre), pp. 512-520.

VILAIN, P. (2009); L'Autofiction en théorie suivi de deux entretiens avec Philippe Sollers \& Philippe Lejeune. Chatou: Les Editions de la Transparence. 


\section{RESEÑAS}


